\section{Extracapillary proliferative glomerulonephritis in Russell's viper bite}

Renal changes in snake bite include tubular necrosis, cortical necrosis, interstitial nephritis, arteritis, and thrombophlebitis. ${ }^{1-3}$ Glomerular changes are usually mild, ${ }^{1}$ and severe glomerulonephritis is uncommon. ${ }^{*}$ We report the case of a patient bitten by a Russell's viper who presented with acute renal failure. A renal biopsy specimen showed extracapillary proliferative glomerulonephritis in addition to tubular necrosis.

\section{Case report}

The patient, a 33-year-old farmer, was bitten on the left foot by a Russell's viper. When brought to a local hospital within two hours he had gross haematuria and oliguria. Except for some pain at the site of the bite there were no abnormal physical signs. Only conservative treatment was instituted, and antivenom was given. One day after the bite his blood urea concentration was $11.1 \mathrm{mmol} / 1(66.6 \mathrm{mg} / 100 \mathrm{ml})$ and serum creatinine concentration $0.2 \mathrm{mmol} / \mathrm{l}$ $(2.26 \mathrm{mg} / 100 \mathrm{ml})$. He was therefore transferred to our unit for the management of renal failure. Laboratory investigation two days after the bite showed haemoglobin $11 \mathrm{~g} / \mathrm{dl}$, blood urea $31.8 \mathrm{mmol} / 1(191 \mathrm{mg} / 100 \mathrm{ml})$, serum creatinine $0.3 \mathrm{mmol} / 1(3.4 \mathrm{mg} / 100 \mathrm{ml})$, normal serum electrolytes, factor $\mathrm{V} 58 \%$, factor VIII $62 \%$, plasma fibrinogen $120 \mathrm{mg} / \mathrm{dl}$, platelets $80 \times 10^{9} / 1(80000 /$ $\mathrm{mm}^{3}$ ), coagulation time over $30 \mathrm{~min}$, serum C3 $70 \mathrm{mg} / \mathrm{dl}$, plasma haemoglobin $2.2 \mathrm{mg} / \mathrm{dl}$, and serum fibrin degradation products $11.6 \mathrm{mg} / \mathrm{dl}$. A peripheral blood smear showed burred cells consistent with disseminated intravascular coagulation. The urine contained numerous red blood cells and $2+$ protein. The patient remained very oliguric, and after six days his blood urea concentration rose to $57 \cdot 1 \mathrm{mmol} / \mathrm{l}(343 \mathrm{mg} / 100 \mathrm{ml})$ and serum creatinine to 0.6 $\mathrm{mmol} / 1 \mathrm{l}(6.8 \mathrm{mg} / 100 \mathrm{ml})$. Because of uraemic symptoms he underwent peritoneal dialysis on the seventh and 16th hospital days. Diuresis occurred in the third week with gradual increase in the urine flow. Coagulation factors and platelets returned to normal 12 days after admission. His serum creatinine concentration was $0.13 \mathrm{mmol} / 1(1.46 \mathrm{mg} / 100 \mathrm{ml}) 30$ days after admission. A renal biopsy specimen obtained two weeks after admission showed focal tubular degeneration, arteritis, and extracapillary proliferative glomerulonephritis in half of the glomeruli (fig (a)). The other glomeruli showed only mesangial proliferation. Neither immunoglobulins nor $\mathrm{C}_{3}$ could be detected in the renal lesion but immunofluorescence showed fibrin deposition in the glomeruli (fig (b)).

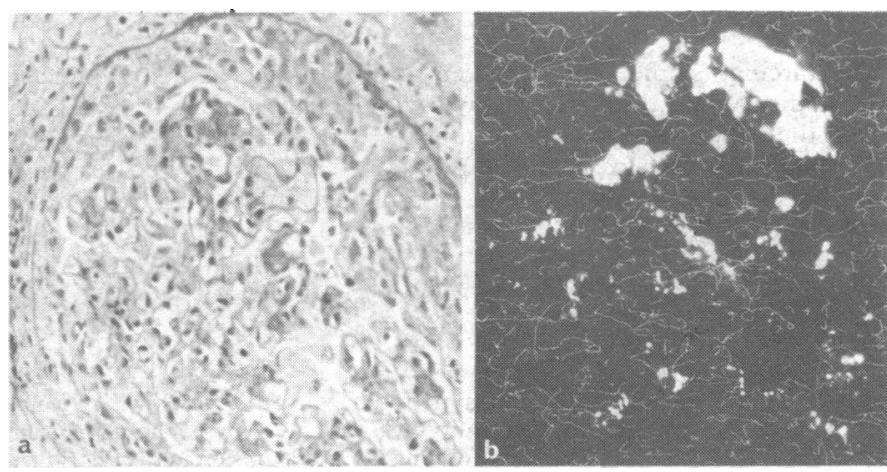

Extracapillary proliferative glomerulonephritis in Russell's viper bite. (a) Glomerulus with proliferation of epithelial cells (haematoxylin-eosin, original magnification $\times 252$ ). (b) Glomerular fibrin deposition (fluorescent antifibrin, original magnification $\times 252$ ).

\section{Comment}

Renal failure due to acute tubular necrosis or cortical necrosis is common in a patient bitten by Russell's viper. Multiple factors including direct tubulotoxicity, intravascular haemolysis, hypovolaemia, and disseminated intravascular coagulation are responsible for its development. ${ }^{1}$ Glomerular changes are usually benign, and an immunological mechanism has been implicated in their pathogenesis. ${ }^{3}$ In our patient glomerulonephritis was severe, there was no evidence of any immunological process, and hence the glomerular changes were presumably due to the direct effect of venom, the mesangial proliferation being a non-specific pathological reaction. Since Russell's viper's venom is vasculotoxic ${ }^{2}$ it could cause rupture of the glomerular basement membrane with fibrin deposition and secondary epithelial proliferation. This is an uncommon finding which might result from a large amount of envenomation. Nevertheless, it expands the range of renal lesions in snake bite and represents a non-immunological cause of glomerulonephritis.

1 Sitprija V, Boonpucknavig V. Snake venoms and nephrotoxicity. In: Lee CY, ed. Snake venoms. Berlin: Springer, 1979:997-1018.

2 Sitprija V, Benyajati C, Boonpucknavig V. Further observations of renal insufficiency in snakebite. Nephron 1974 ;13:396-403.

${ }^{3}$ Sitprija V, Boonpucknavig V. The kidney in tropical snakebite. Clin Nephrol 1977;8:377-83.

- Seedat YK, Reddy J, Edington DA. Acute renal failure due to proliferative nephritis from snake bite poisoning. Nephron 1974;13:455-63.

(Accepted 4 March 1980)

Department of Medicine, Chulalongkorn Hospital Medical School, Bangkok, Thailand

VISITH SITPRIJA, MD, PHD, professor of medicine

Department of Pathology, Ramathibodi Hospital, Bangkok, Thailand VIJITR BOONPUCKNAVIG, MD, associate professor of pathology

\section{High-pressure water jet injury}

Complex high-pressure water jet guns have been developed for underwater cutting and cleaning. They operate at pressures up to $100 \mathrm{MPa}$ (1000 bar; $14500 \mathrm{lbs} / \mathrm{in}^{2} ; 1019 \mathrm{~kg} / \mathrm{cm}^{2}$ ) with a jet velocity of 900 miles $(559 \mathrm{~km})$ per hour. The jet therefore causes injury like a high velocity missile. The entrance wound tends to be small and give little indication of the damage to the deeper tissues. For a variable extent along the track of the jet the surrounding tissues will be damaged if not killed by the shock waves developed as the kinetic energy of the jet is dispersed. Deeper tissues will be lacerated depending on the depth of penetration and the anatomy of the area.

\section{Case report}

The patient, a 32-year-old experienced diver, was lowered to 150 feet ( 46 metres) under the sea to clean by high-pressure jet one of the "sea legs" of an oil rig. The jet gun had been left at the site by a previous diver. The water was murky and he could not see the gun. He picked up the hose and began to withdraw it when the gun fired for a moment causing him to drop the hose. He felt he had received a blow on the abdomen but did not realise quite what had happened. He groped for the gun and used it for a minute or two. The pain in his abdomen became more severe and he asked to be taken up. He was decompressed routinely with a pause of three minutes at 50 feet ( 15 metres). The time from the start of the descent to the return to the surface was 14 minutes. He was wearing an inner tight-fitting Neoprene suite about $3 \mathrm{~mm}$ thick and an outer loose-fitting, 7-mm thick Neoprene suit with a tough "anti-scuff" surface. The jet had drilled a neat hole through both suits and entered the abdominal wall. He was transferred by helicopter to hospital.

On admission three hours later the patient's general condition was quite good. His blood pressure was $140 / 75 \mathrm{~mm} \mathrm{Hg}$, pulse 74 and regular. There was a small puncture wound about $0.25 \mathrm{~cm}$ in diameter on the anterior abdominal wall $6 \mathrm{~cm}$ below the umbilicus and $3 \mathrm{~cm}$ to the right of the midline. There was tenderness and guarding about the wound but the left side of the abdomen was soft. Bowel sounds could be heard but were diminished. A chest radiograph was normal and $x$-ray examination of his abdomen showed no evidence of free intraperitoneal gas and no abnormal soft tissue shadows. Because of the mechanism of the injury laparotomy was done through a right paramedian incision excising the entrance wound. The wound enlarged as it went deeper. There was a hole $2 \mathrm{~cm}$ in diameter in the anterior rectus sheath. The underlying rectus muscle had been torn, leaving a gap of about $4 \mathrm{~cm}$, and there was a hole $3 \mathrm{~cm}$ in diameter in the peritoneum. There was quite extensive oedema of the subcutaneous tissue. The gut was not injured but there was an area $1.5 \mathrm{~cm}$ in diameter of bruising of the mesentery and a $1-\mathrm{cm}$ tear in the omentum. The posterior peritoneum was intact. Some blood and, presumably, sea-water in the peritoneal cavity was sucked out. The patient had an uneventful convalescence and went home after eight days.

\section{Comment}

Nearly all the reported cases of high-pressure jet injury have been from jets of oil, grease, or paint and usually to the hand. Neill and George $^{1}$ described multiple perforations of the ileum and caecum caused by high-pressure water jet and Gardner ${ }^{2}$ reported a case in 